\title{
Mechanical Properties of Metal Coating Layers after Laser Heat Treatment
}

\author{
Arthur OLAH \\ Transilvania University of Brasov, Romania, oart@unitbv.ro
}

\begin{abstract}
The goal of this research is to study the influence of the laser heat treatment on wearing resistance of metal coating layers. Results reveal the influence of microstructures and chemical composition of used electrodes on microhardness and wear resistance of metal coating layers. Laser heat treatment was applied after coating. Evaluation of results was made by observing the microstructures with metallographic microscopy, SEM/EDX and the mechanical properties were obtained by microhardness and wear resistance.
\end{abstract}

\section{Keywords}

metal coating, laser heat treatment, wearing resistance

\section{Introduction}

Recent reviews of the principles and applications of laser treatments describe the use of lasers as a controlled heat source for transformation hardening [4]. The classical approach to modelling the heat flow induced by a distributed heat source moving over the surface of a semi-infinite solid starts with the solution for a point source and integrates it over the area of the beam. This widely used method requires numerical procedures for its evaluation, as do the finite difference solutions of Shuja et al. [5]. They developed a 3-D heat flow model and varied the beam power and traverse speed to determine the dimensional analysis of heat flow during heat treating and melting. But the results were not easy discretion of complex shapes and needed complicated calculation. Several authors have used finiteelement method for numerical evaluation, as do the FEM analyses of W. Dai and co-workers [6]. The goal of this paper is to make a correlation between the microstructures and the mechanical properties of the metal coating layers after laser heat treatment

The metal coating process is based on the need to protect metal parts and structures from damage by exploitation conditions. Metals used for structural components, mechanisms, enclosures, etc. include steel, stainless steel, aluminium, and titanium. These metals will increase the wear resistance and give the opportunities to recover some components.

Surface treatments made by laser beam irradiation include laser hardening, laser alloying, and laser cladding $[1,2]$. The common feature of all of these processes is the production of certain thermal cycles in small, highly localized regions on the surface of the work-piece, which then takes on new properties that allow it to cope better with wear, fatigue, and corrosion while maintaining most of its other original properties [3].

\section{Research Method}

The metal coating was made with arc welding Luftarc 150 Ductil equipment, using four types of electrodes (Table 1). The welding current intensity was $700 \mathrm{~A}$, the welding voltage was $40 \mathrm{~V}$, welding velocity $40-45 \mathrm{~mm} / \mathrm{min}$ and width of welding bead was $10 \mathrm{~mm}$. The base metal was S275JR SR EN 10025-2:2004, $20 \mathrm{~mm}$ thick. The coating layer was $5 \mathrm{~mm}$ thick for all the samples. After coating, the samples were annealed at $600{ }^{\circ} \mathrm{C}$, to eliminate the internal stresses.

\section{Results and Discussion}

Laser heat treatment was applied on eight types of welding coating layers, presented in Table 1 . The sample was subject to laser heat treatment in nine variants, with laser source Nd:YAG - Rofin DY 570 Germany, directed with ABB - Sweden robots. Table 2 presents the intensity of laser beam at surface heat treatment, which was choice to cover a large range of laser heat treatments. 
RECENT, Vol. 21, no. 2(61), 2020

Table 1. Electrodes used in research

\begin{tabular}{|c|c|c|c|c|c|c|c|c|c|}
\hline & \multicolumn{9}{|c|}{ Chemical composition [\%] } \\
\cline { 2 - 10 } Electrode & $\mathrm{C}$ & $\mathrm{Si}$ & $\mathrm{Mn}$ & $\mathrm{Cr}$ & $\mathrm{Ni}$ & $\mathrm{Mo}$ & $\mathrm{W}$ & $\mathrm{P}$ & $\mathrm{V}$ \\
\hline El CrMn2 & $0.5-0.7$ & $0.2-0.3$ & $1.5-2.2$ & $10-12$ & & & & & \\
\hline El CrW2 & $0.4-0.6$ & $0.8-1.3$ & $1.5-2.2$ & $0.8-1.2$ & & & $2.3-3.0$ & & \\
\hline El CrW8Co & $0.3-0.4$ & $0.8-1.3$ & $0.8-1.5$ & $1.3-2.0$ & & & $7.0-9.0$ & & \\
\hline E 3161 & 0.10 & 0.9 & $0.5-2.5$ & $17-20$ & $11-14$ & & & 0.04 & \\
\hline
\end{tabular}

Table 2. Intensity of laser beam and sample notation

\begin{tabular}{|c|c|c|c|c|c|c|c|c|c|}
\hline \multirow{2}{*}{ Electrodes type } & \multicolumn{7}{|c|}{ Intensity of laser beam [W] } \\
\cline { 2 - 10 } & 1400 & 1500 & 1600 & 1700 & 1875 & 2150 & 2425 & 2600 & 2700 \\
\hline El CrMn2 & {$[0-1]$} & {$[0-2]$} & {$[0-3]$} & {$[0-4]$} & {$[0-5]$} & {$[0-6]$} & {$[0-7]$} & {$[0-8]$} & {$[0-9]$} \\
\hline El CrW2 & {$[1-1]$} & {$[1-2]$} & {$[1-3]$} & {$[1-4]$} & {$[1-5]$} & {$[1-6]$} & {$[1-7]$} & {$[1-8]$} & {$[1-9]$} \\
\hline El CrW8Co & {$[2-1]$} & {$[2-2]$} & {$[2-3]$} & {$[2-4]$} & {$[2-5]$} & {$[2-6]$} & {$[2-7]$} & {$[2-8]$} & {$[2-9]$} \\
\hline E 3161 & {$[\mathrm{E}-1]$} & {$[\mathrm{E}-2]$} & {$[\mathrm{E}-3]$} & {$[\mathrm{E}-4]$} & {$[\mathrm{E}-5]$} & {$[\mathrm{E}-6]$} & {$[\mathrm{E}-7]$} & {$[\mathrm{E}-8]$} & {$[\mathrm{E}-9]$} \\
\hline
\end{tabular}

The results were evaluated with PMT 3 micro-hardness tester, electronically microscope Nova Nano SEM and chemical analyser EDAX Orbis Micro-XRF.

Laser treated layer thickness is between $0.2-0.9 \mathrm{~mm}$, depends on intensity of laser beam. The structures obtained using SEM technique are presented in Figures 1...4.

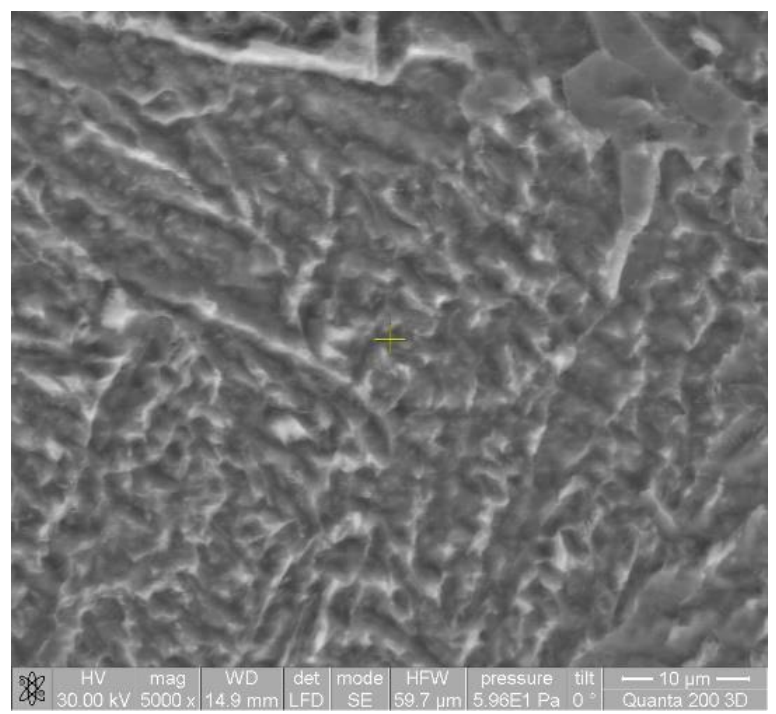

Cross area

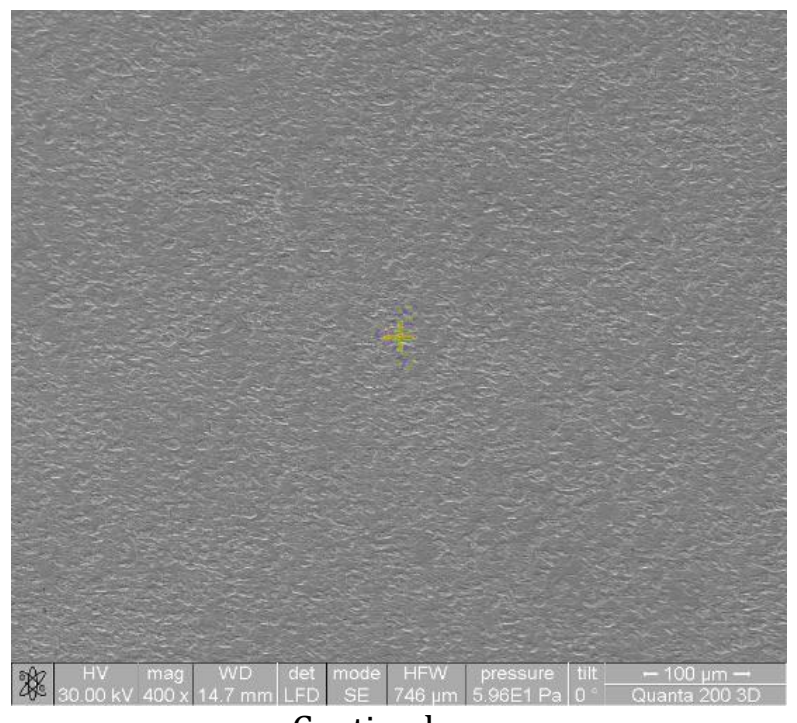

Coating layer

Fig. 1. SEM structure of the cross area and the metal coating layer, for Metal coating with El CrMn2 + Laser heat treatment 1600 W

Studying the microstructures of coated sample with E 3161, which have a low concentration of C, one may observe the ferrite-pearlite structure of base material and weld material structure with martensitic structure having a needle shape. For other five types of electrodes, which have more C, more pearlite structures were obtained. The base material has ferrite-pearlite structures, with lamellar pearlite. Based on the research area, columnar dendrites structures in Fe matrix with god delimitation may be observed.

Increasing the $\mathrm{Cr}$ concentration determines the formation of $\mathrm{Cr}_{3} \mathrm{C}_{2}$ chemical compound in ferritepearlite matrix, especially in the case of electrodes $\mathrm{CrMn} 2$ and 3161. In the case of metal coating layers with electrodes $\mathrm{CrW} 2$, which have low concentration of $\mathrm{Cr}$, the formation of chemical compound cannot be observed. 


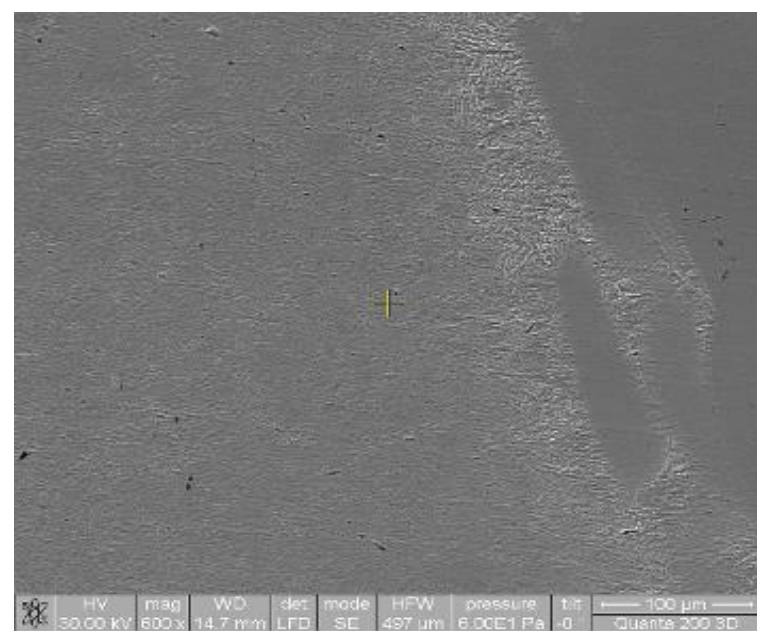

Cross area

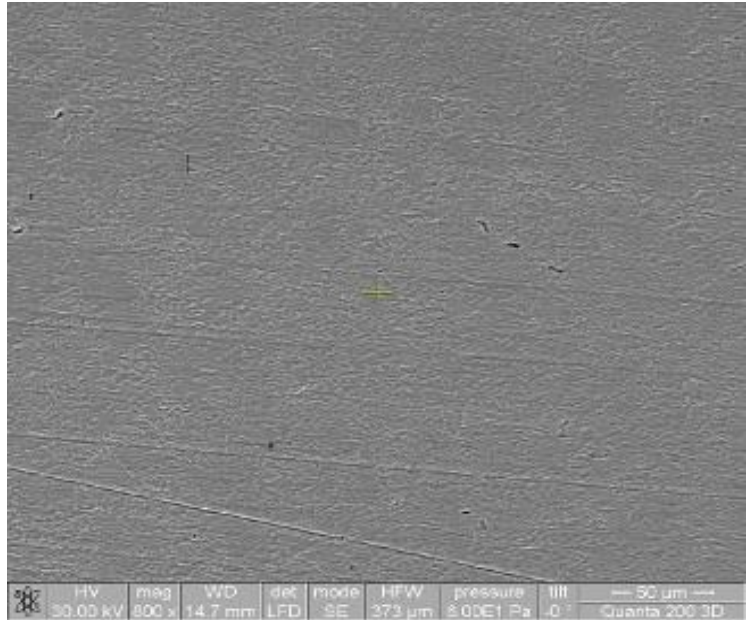

Coating layer

Fig. 2. SEM structure of the cross area and the metal coating layer, for Metal coating with El CrW2 + Laser heat treatment $1700 \mathrm{~W}$

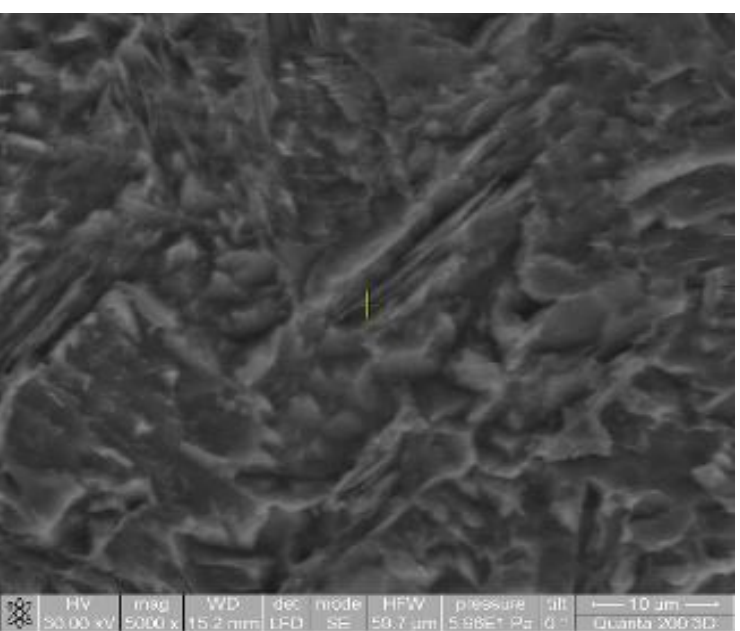

Coating layer

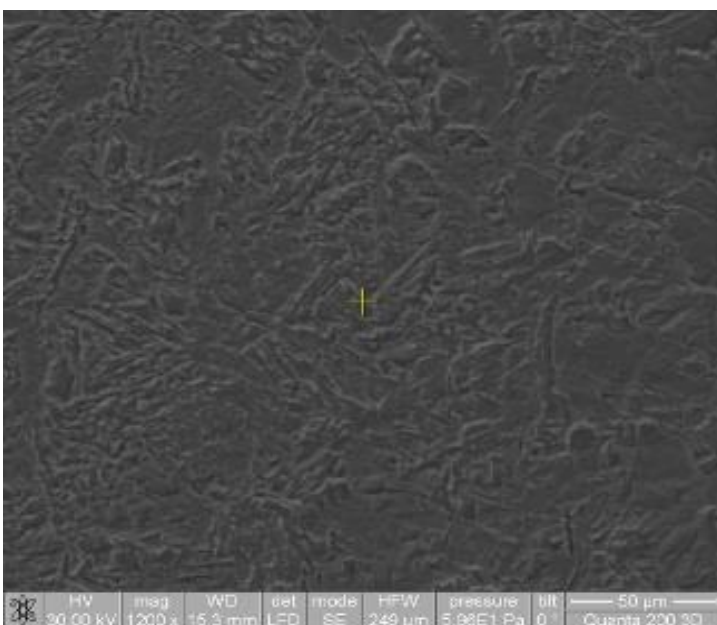

Coating layer

Fig. 3. SEM structure of the cross area and the metal coating layer, for Metal coating with El CrW2 + Laser heat treatment $2700 \mathrm{~W}$

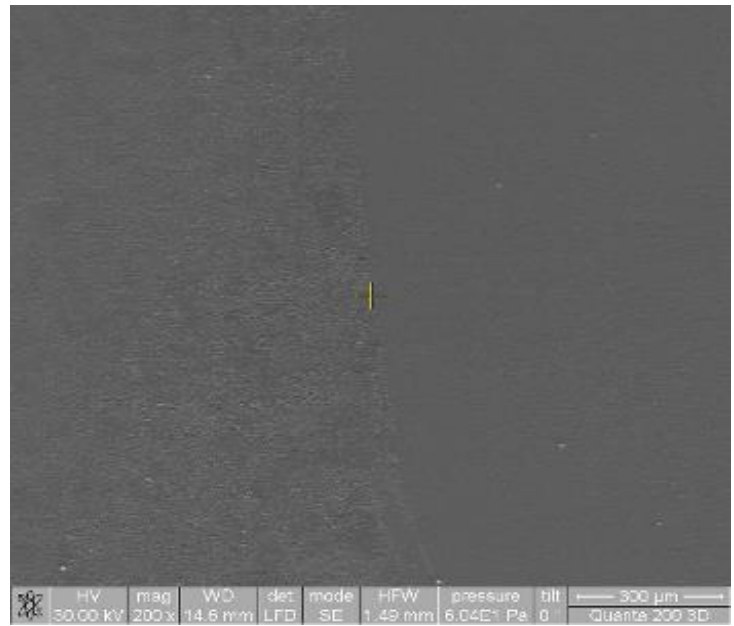

Cross area

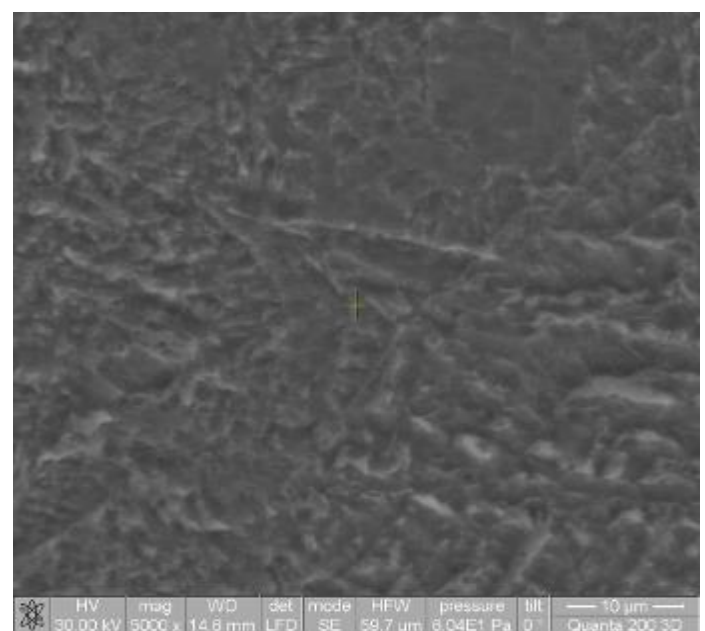

Coating layer

Fig. 4. SEM structure of the cross area and the metal coating layer, for Metal coating with El CrW8Co + Laser heat treatment 2425 W 
Evaluation of mechanical properties was made with micro hardness and wear resistance. The obtained microhardness is presented in Figure 5.

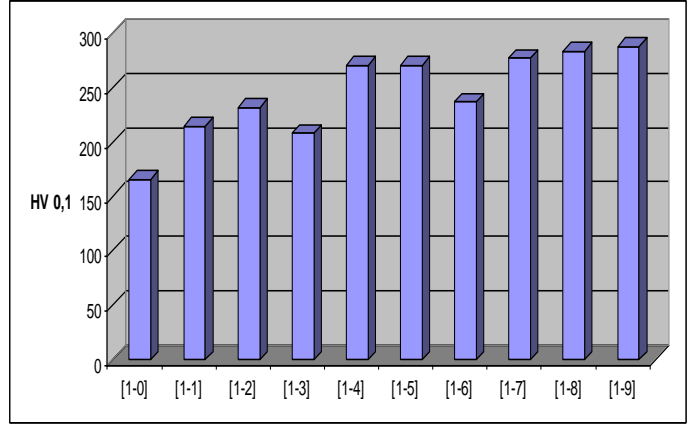

a) Metal coating with El CrW2

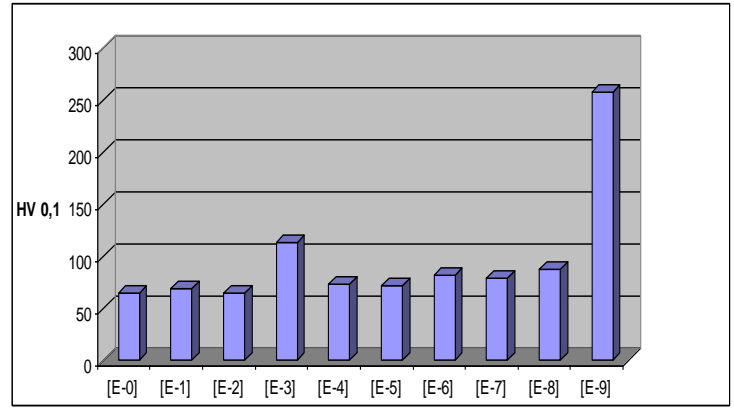

c) Metal coating with E 3161

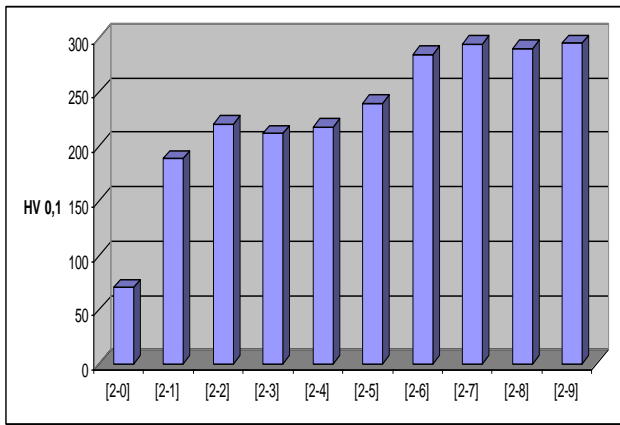

b) Metal coating with El CrW8Co

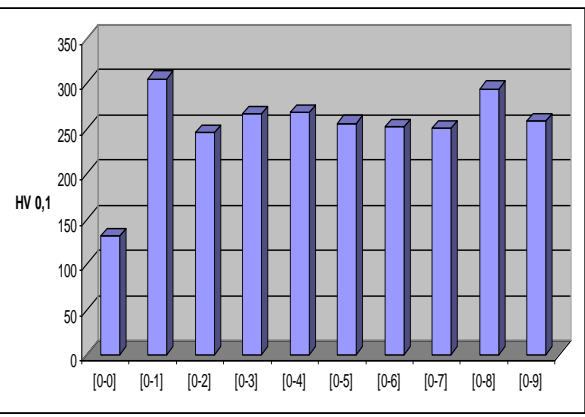

d) Metal coating with El CrMn2

Fig. 5. Microhardness of the metal coating layers

As one may notice from the experimental outcomes, the samples with laser surface heat treatment have a wearing resistance that is mostly superior to the classically thermal treated samples. In the case of laser surface heat treatment layers the existence in combination layer of isolated dot-shaped pores does not significantly influence the hardness of the laser surface heat treatment area or the cohesion with the diffusion sub-layer. It does though allow the enhancement of surface lapping capacity, as a result of lubricant retention in the superficial pores, linked to the surface through channels.

Wear resistance was tested after 15, 30, 60 and 120 minutes of wear and weighing of samples. Determination of weight loss was made with "Oertling - England" balance, accuracy $10^{-2}$ grams. Results are presented in the wear diagrams, Figures $6 . . .9$.

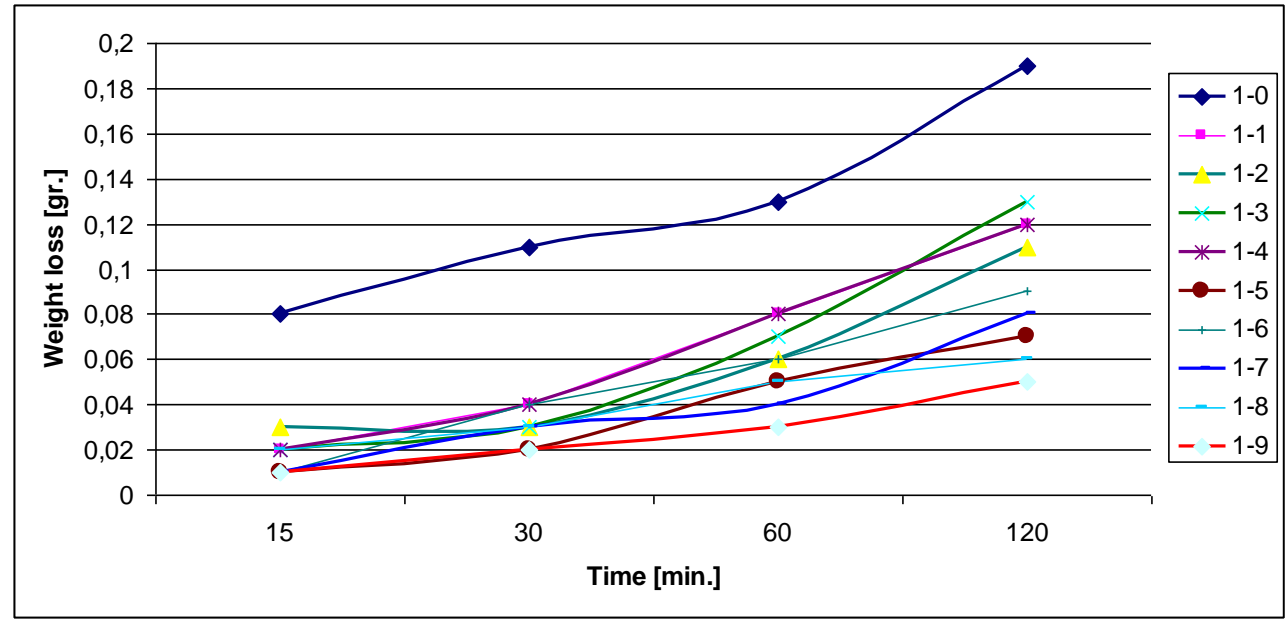

Fig. 6. Wear diagrams of metal coating layers. Metal coating with El CrW2 
RECENT, Vol. 21, no. 2(61), 2020

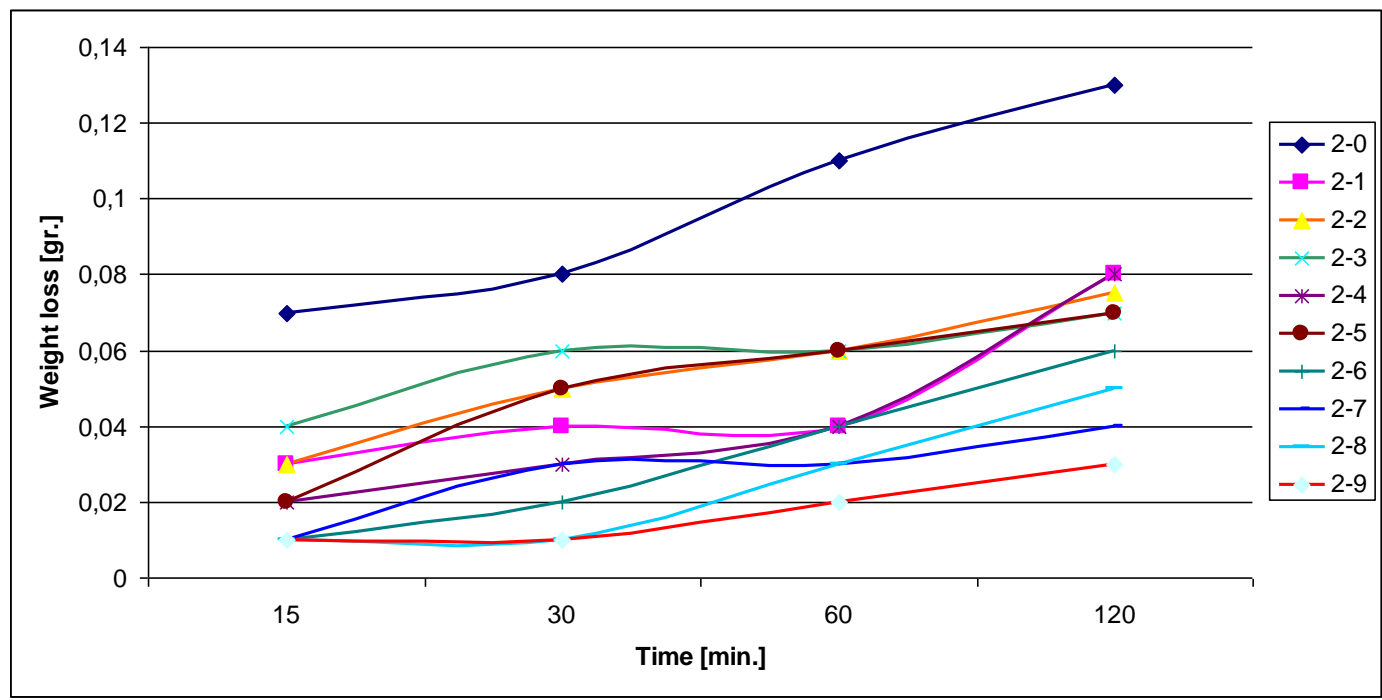

Fig. 7. Wear diagrams of metal coating layers. Metal coating with El CrW8Co

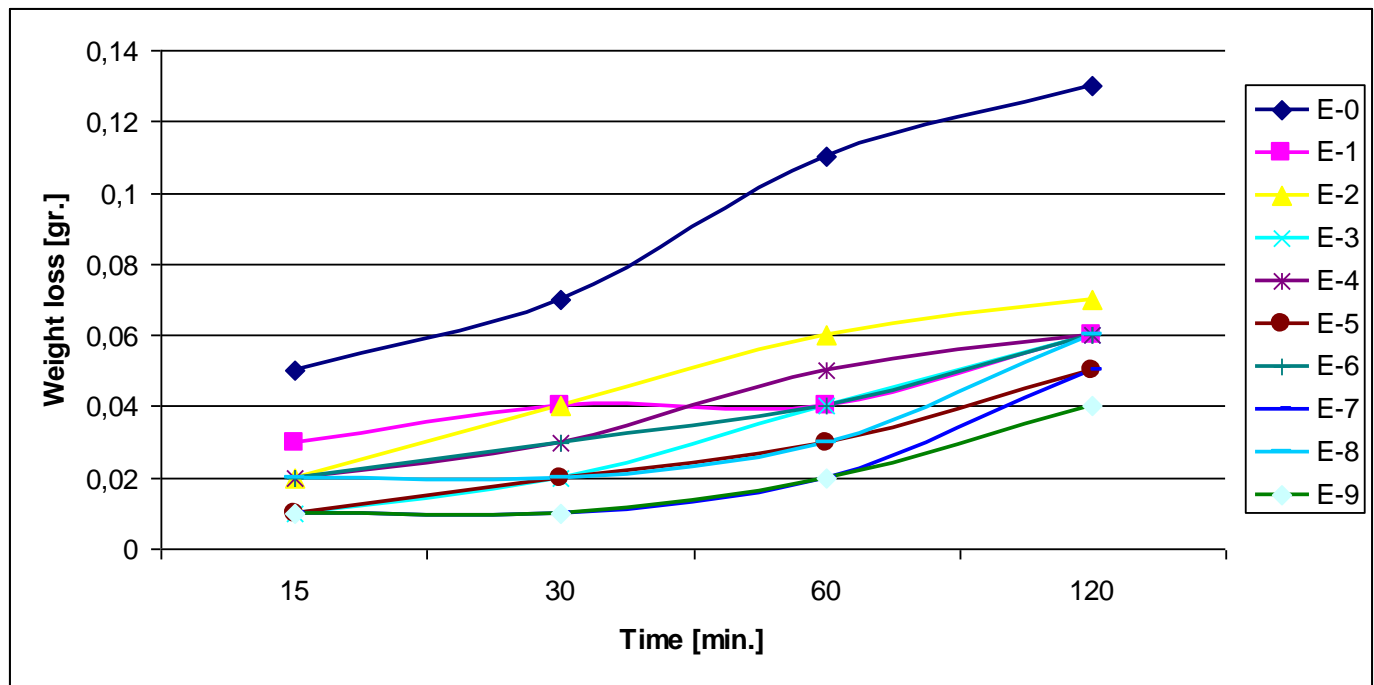

Fig. 8. Wear diagrams of metal coating layers. Metal coating with E 3161

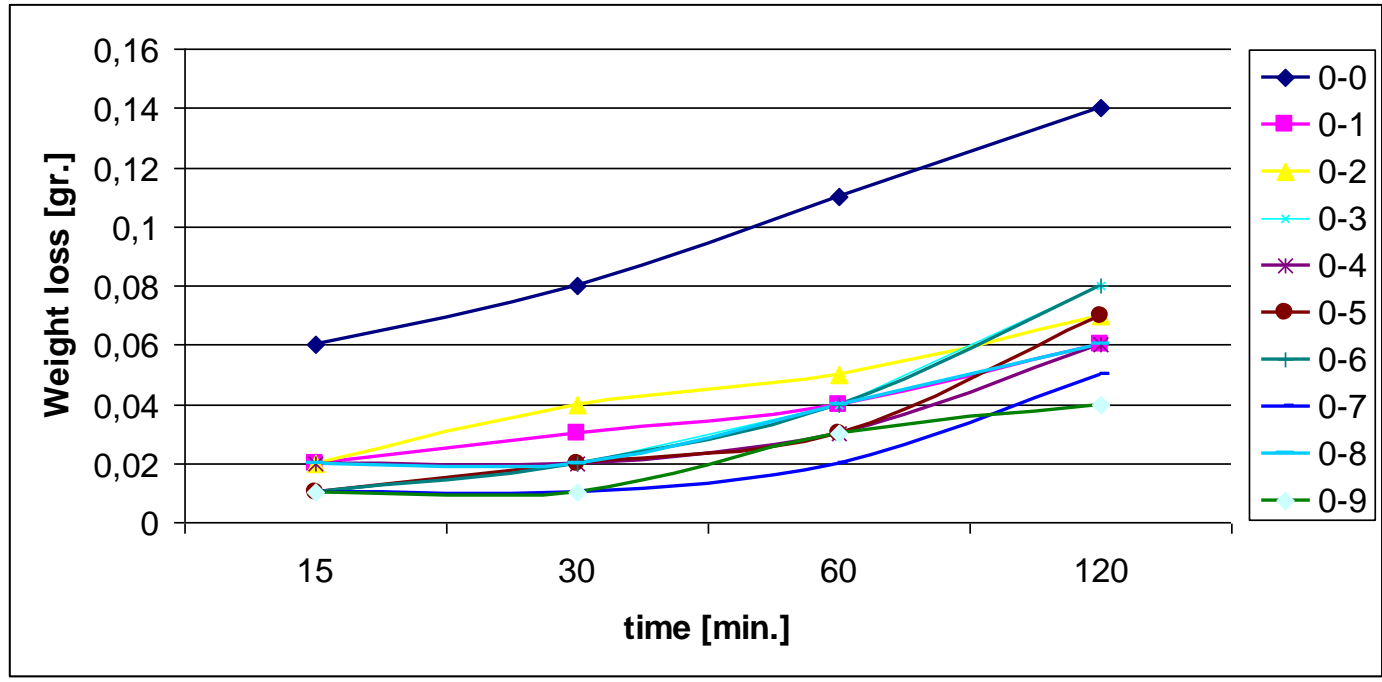

Fig. 9. Wear diagrams of metal coating layers. Metal coating with $\mathrm{CrMn} 2$ 


\section{Conclusion}

Wear resistance is perhaps the most significant property resulting from this surface treatment. The ability of the compound zone to resist wear is dependent on the type of wear system, specifically whether it is adhesive or abrasive wear. Adhesive wear occurs when two components are in relative motion in an essentially abrasive free environment. Under these conditions, the intrinsic physical characteristics of the compound zone, i.e. hardness and lubrication, notably improve the sliding and running behaviour and consequently, increase the resistance to adhesive wear. The phase composition of the compound zone that demonstrates the best wear resistance consists predominantly of epsilon nitride phase (monophasic preferred) with a very small amount of gamma prime phase. Resistance to abrasive wear is dependent on the relative harnesses of the abrading substance and of the compound zone.

The outermost layer identified as the compound zone, and the subjacent interior layer is called the diffusion zone. Each of the zones contribute to improving performance by enhancing specific engineering properties, i.e. wear resistance, lubrication, corrosion resistance, and fatigue strength. From these, other benefits in performance are realized: excellent running properties, anti-galling and antiseizing characteristics, and reduced tendency for fretting corrosion.

Studying the SEM structures, presented in Figure 1, the microhardness (Figure 5) and wear resistance (Figures 6...9), one may observe a good correlation between the microhardness and wear resistance, increasing the microhardness determinate increase of wear resistance. After the low intensity laser surface heat treatment, that changes the structures of materials, results the partial transformation of ferrite in perlite with higher $\mathrm{C}$ concentration, increasing mechanical properties. In case of high intensity of laser surface heat treatment, more than $2000 \mathrm{~W}$, one may observe the formation of re-melted structures, the result being the significantly increase of mechanical properties.

\section{References}

1. Orazi L., Fortunato A., Cuccolini G., Tani G. (2010): An efficient model for laser surface hardening of hypo-eutectoid steels. Applied Surface Science, ISSN 0169-4332, Vol. 256, is. 6, pp. 1913-1919, https://doi.org/10.1016/ j.apsusc.2009.10.037

2. Abbas G., Li L., Ghazanfar U., Liu Z. (2006): Effect of high power diode laser surface melting on wear resistance of magnesium alloys. Wear, ISSN 0043-1648, Vol. 260, is. 1-2, pp. 175-180, https://doi.org/10.1016/ j.wear.2005.01.036

3. Slatter T., Taylor H., Lewis R., King P. (2009): The influence of laser hardening on wear in the valve and valve seat contact. Wear, ISSN 0043-1648, Vol. 267, is. 5-8, pp. 797-806, https://doi.org/10.1016/j.wear.2009.01.040

4. Pellizzari M., De Flora M.G. (2011): Influence of laser hardening on the tribological properties of forged steel for hot rolls. Wear, ISSN 0043-1648, Vol. 271, is. 9-10, pp. 2402-2411, https://doi.org/10.1016/j.wear.2011.01.044

5. Roată I.C., Iovănaș R., Pascu A. (2013): Influence of the metallizing distance variation and of the electric field voltage on the ohmic resistance of the layers deposited by thermal spraying. Metalurgia International, ISSN 1582-2214, Special Issue no. 6, pp. 73-76

6. Dai W., Xiang X., Jiang Y., Wang H.J., Li X.B., Yuan X.D., Zheng W.G., Lv H.B., Zu X.T. (2011): Surface evolution and laser damage resistance of $\mathrm{CO}_{2}$ laser irradiated area off used silica. Optics and Lasers in Engineering, ISSN 01438166, Vol. 49, is. 2, pp. 273-280, https://doi.org/10.1016/j.optlaseng.2010.10.001

7. Oláh A., Tierean M.H. (2013): Research about Relation between the Microstructures and Mechanical Properties of Metal Coating Layers. Solid State Phenomena, ISSN 1662-9779, Vol. 216 (Proceeding of AMS Conference, Timisoara, Romania), pp. 169-174, https://doi.org/10.4028/www.scientific.net/SSP.216.169

8. Oláh A., Croitoru C., Tierean M.H. (2018): Surface properties tuning of welding electrode-deposited hardfacings by laser heat treatment. Applied Surface Science, ISSN 0169-4332, Vol. 438, pp. 41-50, https://doi.org/10.1016/ j.apsusc.2017.10.090

9. Machedon Pisu T., Machedon Pisu E., Bigioi O.L. (2009): Researches regarding the welding of 15NiMn6 steel used for spherical tanks. Metalurgia International, ISSN 1582-2214, Vol. 14, pp. 159-162 